
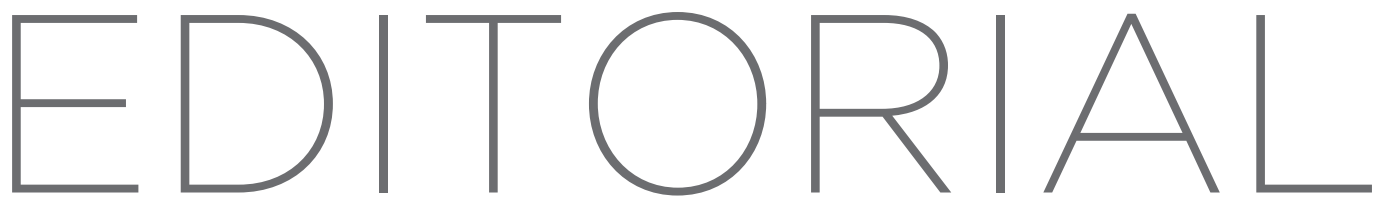

http://dx.doi.org/10.18222/eae266203578

\title{
AVALIAÇÃO EM LARGA ESCALA NO BRASIL: TENSÕES E DESAFIOS
}

Caro leitor,

Nesta edição de Estudos em Avaliação Educacional, é apresentado como Tema em Destaque um conjunto de artigos que abordam diferentes aspectos das avaliações educacionais em larga escala. Contribuem com esse tema três textos que são versões ampliadas de trabalhos apresentados no III Congresso Nacional de Avaliação em Educação, ocorrido em 2014, em Bauru-SP.

Ao longo das últimas décadas no Brasil, nota-se que a avaliação em larga escala vem se consolidando como um instrumento das políticas públicas em educação, em seus diferentes âmbitos de gestão, seja ele em nível federal, estadual ou municipal. No entanto, ainda se observam inúmeros desafios quanto ao uso efetivo dessas avaliações na formulação, reformulação e no monitoramento de ações, projetos e programas educacionais, e, notadamente, no que diz respeito ao trabalho no interior das unidades escolares.

Há uma tendência geral de os estados e municípios brasileiros investirem no desenvolvimento de avaliações externas censitárias. Assim como indicam Bauer e colegas neste número da revista, tal desenho é adotado, na maioria dos casos, após a criação da Prova Brasil pelo governo federal, em 2005. Com isso, torna-se possível a obtenção de resultados individuais dos estabelecimentos de ensino participantes, demandando, de certa forma, às escolas - professores e gestores escolares -, a necessidade cada vez maior de uma apropriação mais efetiva das informações produzidas por essas avaliações, principalmente com a orientação dos diferentes órgãos de gestão educacional de que elas podem e devem 
subsidiar as decisões pedagógicas tomadas no interior dos estabelecimentos de ensino.

Cabe destacar que há esforços de instâncias centrais do governo federal, estadual e municipal, além de organizações privadas, para a criação de plataformas e/ou de orientações que auxiliem os estabelecimentos de ensino na apropriação dos resultados produzidos pelas avaliações em larga escala. Dentre as instâncias que oferecem possibilidades de acessos aos dados dessas avaliações para cada uma das escolas participantes, podem-se indicar, por exemplo, o Portal Ideb e o Portal Devolutivas Pedagógicas - desenvolvidos pelo Instituto Nacional de Estudos e Pesquisas Educacionais Anísio Teixeira (Inep) -, este último com foco no uso, por gestores e escolares e professores, das informações obtidas por meio da Prova Brasil.

No entanto, apesar do empenho em direção ao aperfeiçoamento dos mecanismos de disseminação e apropriação das informações produzidas pelas avaliações externas e das demais estatísticas educacionais atualmente disponíveis, ainda são muitos os desafios para a consolidação de usos efetivos dos dados educacionais, sobretudo os produzidos por essas avaliações. Podem-se ressaltar, dentre eles, as dificuldades da articulação por parte das secretarias de educação estaduais e municipais dos dados das avaliações externas com as demais estatísticas educacionais; a demora, em muitos casos, da divulgação das informações produzidas por esse tipo de avaliação, dificultando assim, uma apropriação mais imediata; bem como as dificuldades no desenvolvimento de mecanismos de formação continuada dirigidos aos diferentes segmentos da gestão educacional (órgãos centrais, intermediários e escolas) para uma orientação mais consistente quanto às possibilidades e limites da utilização dessas informações em seus contextos de trabalho.

Por outro lado, cabe destacar o intenso e não superado debate acadêmico no Brasil em relação às possíveis implicações das avaliações externas em âmbito escolar, especialmente devido à centralidade que elas passam a ter no interior das escolas. Diversas são as questões levantadas a esse respeito e que devem ser consideradas para a construção e consolidação da temática da avaliação em larga escala no país, sendo 
algumas delas expostas nos artigos que compõem o Tema em Destaque desta edição.

Com o objetivo de contribuir para esse debate, os autores Martins e Calderón, no artigo "Boas práticas escolares e avaliação em larga escala: a literatura ibero-americana em questão", por meio de uma pesquisa sobre o estado do conhecimento, utilizando-se da produção bibliográfica ibero-americana, trazem contribuições importantes para a consolidação do debate existente no campo da avaliação educacional a respeito das diferentes concepções, tendências e abordagens do conceito de boas práticas escolares e sua vinculação ou não com as avaliações em larga escala e com a melhoria dos resultados da aprendizagem dos estudantes.

Como conclusão, o texto apresenta tensões e conflitos quanto à relação expressa entre boas práticas escolares e a avaliação em larga escala, notadamente no contexto brasileiro e português.

No cenário brasileiro, os autores destacam que, por um lado, em estudos e pesquisas governamentais, bem como em publicações elaboradas pelas agências multilaterais, são observadas tal vinculação, inclusive com a proposição de mecanismos de incentivo à identificação, premiação e disseminação de boas práticas escolares por parte dos gestores educacionais. Por outro lado, foram também identificadas críticas de pesquisadores da área sobre a relação entre boas práticas escolares e avaliação em larga escala, principalmente por serem consideradas políticas neoliberais, orientadas na accountability. Em Portugal, apesar de identificadas posições diversas sobre essa vinculação, o artigo afirma coexistir abordagem positiva e negativa, superando, de certa forma, a dicotomia progressista-neoliberal.

Contrapondo-se a isso, os autores ressaltam que, no contexto espanhol, a produção acadêmica concentra-se mais nos estudos sobre as boas práticas que se orientam pela busca de alternativas para a melhoria da aprendizagem e construção de uma escola eficaz.

Ainda sobre produção acadêmica na área de avaliação educacional, este número também traz a pesquisa "Políticas de avaliação institucional e em larga escala: perfil da produção 
na pós-graduação”, de Maria Angélica Pedra Minhoto. Trata-se de um estudo interinstitucional, utilizando-se como fonte primária o banco de teses organizado pela Coordenação de Aperfeiçoamento de Pessoal de Nível Superior (Capes), sendo analisadas 81 teses e dissertações produzidas entre os anos de 2000 a 2010.

Compuseram o estudo as teses e dissertações relacionadas às iniciativas de aferição externa e padronizada do rendimento escolar, desenvolvidas pelas diferentes instâncias de gestão (federal, estadual ou municipal), bem como para os diferentes níveis de ensino e etapas de ensino. Além disso, foram também objeto de análise os trabalhos com foco na autoavaliação de instituições de ensino e iniciativas que propõem uma discussão sobre a articulação teórico-prática dos diferentes processos de avaliação.

$\mathrm{O}$ artigo está estruturado em três partes. Na primeira parte, a autora discute aspectos que dizem respeito à estruturação do campo da política de avaliação, tanto aquelas relativas à avaliação em larga escala quanto à institucional. No segundo momento, são expostos os principais resultados da pesquisa, oferecendo uma descrição importante de características fundamentais do campo da avaliação educacional. Dentre outros resultados, destaca-se aqui a intensificação recente da produção acadêmica brasileira na área, sobretudo a partir de 2007, uma vez que mais de 60\% dos trabalhos de mestrado e doutorado na área da avaliação educacional foram defendidos entre os anos de 2007 a 2010.

O texto "Avaliação em larga escala em municípios brasileiros: o que dizem os números?”, de autoria de Bauer, Pimenta, Horta Neto e Sousa, tem como objetivo principal caracterizar o locus da avaliação em larga escala no âmbito das gestões municipais de educação no Brasil. Por meio de um survey dirigido às secretarias municipais de educação, o estudo busca obter dados quanto à existência ou não de avaliações externas próprias pelos municípios e sobre os motivos e justificativas de sua aquisição ou criação. Por fim, procura também obter informações mais detalhadas sobre os delineamentos metodológicos adotados pelas gestões municipais de educação para o desenvolvimento dessas ações avaliativas. 
Nesse estudo foi possível captar respostas de $4.309 \mathrm{mu}-$ nicípios correspondendo a $77,4 \%$ do total de redes municipais de educação, o que já sugere a riqueza de informações produzidas por essa pesquisa. Dentre os principais resultados, destaca-se o de que cerca de $37 \%$, ou seja, 1.573 municípios, declararam fazer uso de avaliações próprias, e outros $21 \%$ indicaram a pretensão de elaboração de avaliações próprias. Tais informações indicam certa consolidação das políticas de avaliação externa não apenas por parte do governo federal e dos estados, mas também pelas secretarias municipais de educação das diferentes regiões do país. As contribuições desse artigo são valiosas para a discussão a respeito das políticas de avaliação externa e seus usos como instrumento de gestão educacional, indicando a necessidade da produção cada vez mais consistente de pesquisas sobre essa temática.

Outros dois textos apresentados neste número corroboram a discussão a respeito das implicações da avaliação externa no cotidiano escolar, especificamente sobre o Sistema de Avaliação do Rendimento Escolar do Estado de São Paulo (Saresp), sendo o primeiro intitulado "Percurso histórico do Saresp e as implicações para o trabalho pedagógico em sala de aula" e o segundo, "Implicações das avaliações em larga escala para o trabalho docente coletivo".

O primeiro artigo, de cunho bibliográfico e documental, de autoria de Santos e Sabia, tem duplo objetivo, o de identificar a trajetória da implantação do Saresp e o de analisar suas possíveis implicações, ou seja, as influências e as consequências dessa avaliação externa em âmbito escolar, especificamente no direcionamento e na orientação do trabalho pedagógico desenvolvido.

Ressaltam-se como conclusões da pesquisa o redirecionamento dos objetivos centrais do Saresp ao longo de sua existência, deixando-se de se constituir como uma avaliação eminentemente diagnóstica e transformando-se em uma avaliação somativa. Ou seja, sugere-se a ocorrência de um deslocamento de uma avaliação focada na aprendizagem para a constituição de uma avaliação a serviço de uma política de responsabilização da equipe escolar - gestores e professores. Dentre outras implicações e consequências do Saresp no 
trabalho pedagógico cotidiano das escolas, destacam-se o uso do Saresp para a aprovação ou não dos estudantes ao término de um ciclo escolar, o treinamento dos alunos para as rotinas de avaliação externa, bem como a intensificação das cobranças pelo cumprimento das metas estabelecidas pelo Índice de Desenvolvimento da Educação do Estado de São Paulo (Idesp) e o seu uso para ranqueamento e premiação.

Ao final do texto, os autores trazem diferentes questionamentos e indagações que merecem ser priorizadas nos estudos acadêmicos subsequentes e que podem contribuir com o debate acerca das possibilidades de apropriação do Saresp em âmbito escolar para a melhoria da aprendizagem dos estudantes.

O segundo artigo, de autoria de Cunha, Barbosa e Fernandes, tem como objetivo central discutir a respeito do Saresp no cotidiano de escolas da rede estadual paulista e seus efeitos no planejamento e encaminhamentos pedagógicos coletivos, especificamente no processo de discussão do projeto político-pedagógico da unidade escolar.

Para tanto, essa pesquisa, sob uma perspectiva sócio-histórica, parte das informações obtidas por meio de um estudo em uma escola estadual de educação fundamental II e ensino médio, localizada no interior paulista, com aproximadamente 1.000 alunos oriundos de uma comunidade carente, inclusive com parte deles de famílias atendidas por programas sociais como o Bolsa Família. Para as análises desse artigo, foram utilizados diferentes documentos, como as atas e pautas organizadas em 2014 e que diziam respeito ao trabalho coletivo, ao registro do encontro denominado "Reflexão do Saresp”, ocorrido em agosto de 2014, e aos diários de campo.

$\mathrm{O}$ artigo apresenta criticamente alguns possíveis desdobramentos provocados pelo Saresp no trabalho docente coletivo nas aulas de trabalho pedagógico coletivo (ATPC), destacando que tais efeitos acabam por não contribuir para a construção de uma perspectiva articuladora e formativa, além de a escola, por meio de seu projeto político-pedagógico, privilegiar a lógica dos resultados das avaliações externas em detrimento do debate em direção ao fortalecimento da identidade e autonomia escolar. 
Além dos artigos que compõem o Tema em Destaque, também são publicados neste número quatro textos que versam sobre os temas: autoavaliação na educação superior; Programa Ensino Médio Inovador desenvolvido no estado do Ceará; Conselhos de Classe na educação básica; e práticas de correção na avaliação da aprendizagem.

O texto de Bernardes e Rothen - "Comissão Própria de Avaliação: dois lados de uma mesma moeda" -, versa sobre uma temática que concorre para a discussão a respeito de processos de autoavaliação institucional realizados em Instituições de Ensino Superior (IES) no Brasil, sobretudo a partir do estabelecimento do Sistema Nacional de Avaliação da Educação Superior (Sinaes), implantado pela lei federal n. 10.861, em 2004. Seu objetivo é o de analisar e compreender, com base em um estudo de caso, a vinculação da autoavaliação institucional feita por uma Comissão Própria de Avaliação (CPA) com perspectivas de regulação e emancipação.

Em "Ensino médio inovador: ressignificações de educação de qualidade em contextos locais", Santos aborda a questão da qualidade na educação atribuída pelas ações do Programa Ensino Médio Inovador (ProEMI), dirigidas às escolas públicas de ensino médio vinculadas ao governo estadual do Ceará, fundamentando suas análises na concepção de ciclo de políticas de Ball e Bowe (1998).

Já o artigo "Conselho de Classe: que colegiado é esse?", de autoria de Papi, busca, inicialmente, compreender, por meio das pesquisas discentes produzidas no interior dos programas de pós-graduação strictu sensu brasileiros entre os anos de 2002 a 2011, a relevância dessa temática, além de investigar indicativos das possíveis percepções e práticas em relação aos Conselhos de Classe.

O último artigo desta edição, "A correção como processo avaliativo: diferentes percepções em diálogo”, de Moreira e Rangel, tem como objetivo central discutir as diferentes percepções de docentes e estudantes quanto aos objetivos da prática da correção de exercícios no ensino fundamental I, propondo, inclusive, práticas avaliativas em uma perspectiva formativa.

Por fim, a revista tem a honra de publicar a entrevista realizada com o professor Livio Amaral, que ocupou o 
cargo de Diretor de Avaliação da Capes no período de 2009 a 2015. Nessa oportunidade, o professor Livio Amaral aborda aspectos de relevância, como as questões sobre a validade e fidedignidade da avaliação da pós-graduação, as críticas à visão predominantemente quantitativa do modelo de avaliação adotado, bem como da relação entre a boa produtividade dos professores, aferida por meio de sua produção bibliográfica, e a nota obtida pelos programas de pós-graduação.

Boa leitura a todos!

Nelson Gimenes

Editor coordenador 